пределах 12-16 часов), соответственно, применяются в терапии не только СД1, но и СД2, поскольку обладают выраженным сахароснижающим эффектом, снижают риск сосудистых осложнений и не имеют противопоказаний (5). В связи с этим тоже остаются одними из самых назначаемых лекарственных средств, хотя имеют недостатки, связанные с методом доставки препарата, требуют постоянного контроля гликемии и имеют высокий риск глюкозодефицита (6).

\title{
Заключение.
}

В ходе анализа была обнаружена закономерность: пациентам с СД1 типа чаще назначают препараты инсулина длительного действия высокой стоимости, а при СД2 типа часто выписывают пероральные сахароснижающие лекарственные препараты метформин и гликлазид низкой стоимости, но короткого действия, следовательно приобретать данные лекарственные средства необходимо чаще, по сравнению с препаратами инсулина. Таким образом, средние затраты на фармакотерапию СД1 и СД2 оказываются приблизительно одинаковыми.

Как уже было отмечено ранее, лекарственная терапия сахарного диабета как 1 типа, так и 2 относительно дорогая, поэтому выбор препаратов в качестве терапии во многом зависит от особенностей течения заболевания у конкретных пациентов. Благодаря государственной программе по обеспечению ЖНВЛП в лечении сахарного диабета пациенты имеют возможность регулярно получать терапию и сохранять удовлетворительный уровень жизни.

$$
* * *
$$

1. Федеральный регистр больных сахарным диабетом URL: http://sd.diaregistry.ru/index.html (Дата обращения: 20.11.2021)

2. Приказ Министерства здравоохранения РФ от 13 февраля 2013 г. №66 «Об утверждении Стратегии лекарственного обеспечения населения Российской Федерации на период до 2025 года и плана ее реализации" http://www.garant.ru/products/ipo/prime/doc/70217532/\#ixzz6pflyh65Y

3. Возможности фармакотерапии метформином у коморбидных пациентов с сахарным диабетом 2 типа и хронической обструктивной болезнью легких / Е.В. Макарова, Г.Н. Варварина, Ю.А. Сорокина [и др.] // Дневник казанской медицинской школы. - 2020. - № 1 (27). - С. 21-26.

4. Гипогликемия и гипергликемия: потенциальные риски полипрагмазии при сахарном диабете 2-го типа в госпитальных условиях / Ю.А. Сорокина, О.В. Занозина, Л.В. Ловцова [и др.]. //Медицинский совет. - 2018. - №. 4. - C. 112-115.

5. Дедов И.И., Шестакова М.В., Майоров А.Ю. и др. Клинические рекомендации "Алгоритмы специализированной медицинской помощи больным сахарным диабетом" (10-й выпуск). Под редакцией И. И. Дедова, М.В. Шестаковой, А.Ю. Майорова. // Сахарный диабет. - 2021. - Т. 24. - №1S. - С. 1-222.

6. Фурсов, А.Б. Стандарты медицинской помощи при сахарном диабете в стационаре: эволюция взглядов от контроля гликемии до метаболической хирургии / А.Б. Фурсов, Р.А. Фурсов, О.Б. Оспанов // Русский медицинский журнал. Медицинское обозрение. - 2020. - Т. 4. - № 6. - С. 340-346.

\section{Плащевой В.В. \\ Значение репаративных механизмов ретиналамина при диабетической ретинопатии у пациентов, больных сахарным диабетом}

ЛДЦ «Анкор»

(Россия, Благовещенск)

doi: 10.18411/trnio-12-2021-322

\section{Аннотация}

В статье рассмотрены значение репаративных механизмов ретиналамина при диабетической ретинопатии, у пациентов, больных сахарным диабетом. Проведенные исследования доказали эффективность ретинопротекторного действия ретиналамина и его длительное воздействие на фоне компенсации состояния по основному заболеванию. Отмечено улучшение картины глазного дна, сохраняющейся длительный период времени - в 
течение 6 месяцев. Побочных реакций организма на данный препарат у больных выявлено не было.

Ключевые слова: диабетическая ретинопатия, сахарный диабет, нейроэпителий, пациент, сетчатка.

\section{Abstract}

The article discusses the significance of the reparative mechanisms of retinalamine in diabetic retinopathy, in patients with diabetes mellitus. The conducted studies have proved the effectiveness of retinoprotective action of retinalamine and its long-term effect against the background of compensation for the condition of the underlying disease. There was an improvement in the fundus picture, which persists for a long period of time - for 6 months. There were no adverse reactions of the body to this drug in patients.

Keywords: diabetic retinopathy, diabetes mellitus, neuroepithelium, patient, retina.

Важнейшей задачей реформирования здравоохранения РФ является поиск путей максимальной доступности медицинской помощи. Итогом мер по совершенствованию организации деятельности учреждений здравоохранения на всех ступенях предоставления медицинской услуги является - улучшение здоровья и качества жизни человека.

Заболеваемость сахарным диабетом, а также уровень его осложнений в РФ, в последнее время вызывает озабоченность, в следствии отсутствия тенденции к снижению показателей. Увеличение количества пациентов с сахарным диабетом, врачи связывают с тем, что в современном обществе, особенно в крупных городских агломерациях, очень распространены факторы риска этого заболевания: неблагоприятная экология, лишний вес, неправильное питание, ограниченная физическая активность, адинамичный образ жизни, стрессы, хроническая усталость.

Согласно официальным данным Всемирной организации здравоохранения, 5\% населения земного шара страдает сахарным диабетом. К 2025-2030 году эксперты ВО3 прогнозируют увеличение числа больных сахарным диабетом до 300 миллионов человек. Только в РФ, на сегодняшний день, сахарным диабетом страдает около 12 млн. человек из них 24,5 тысячи детей и подростков [3, с. 5].

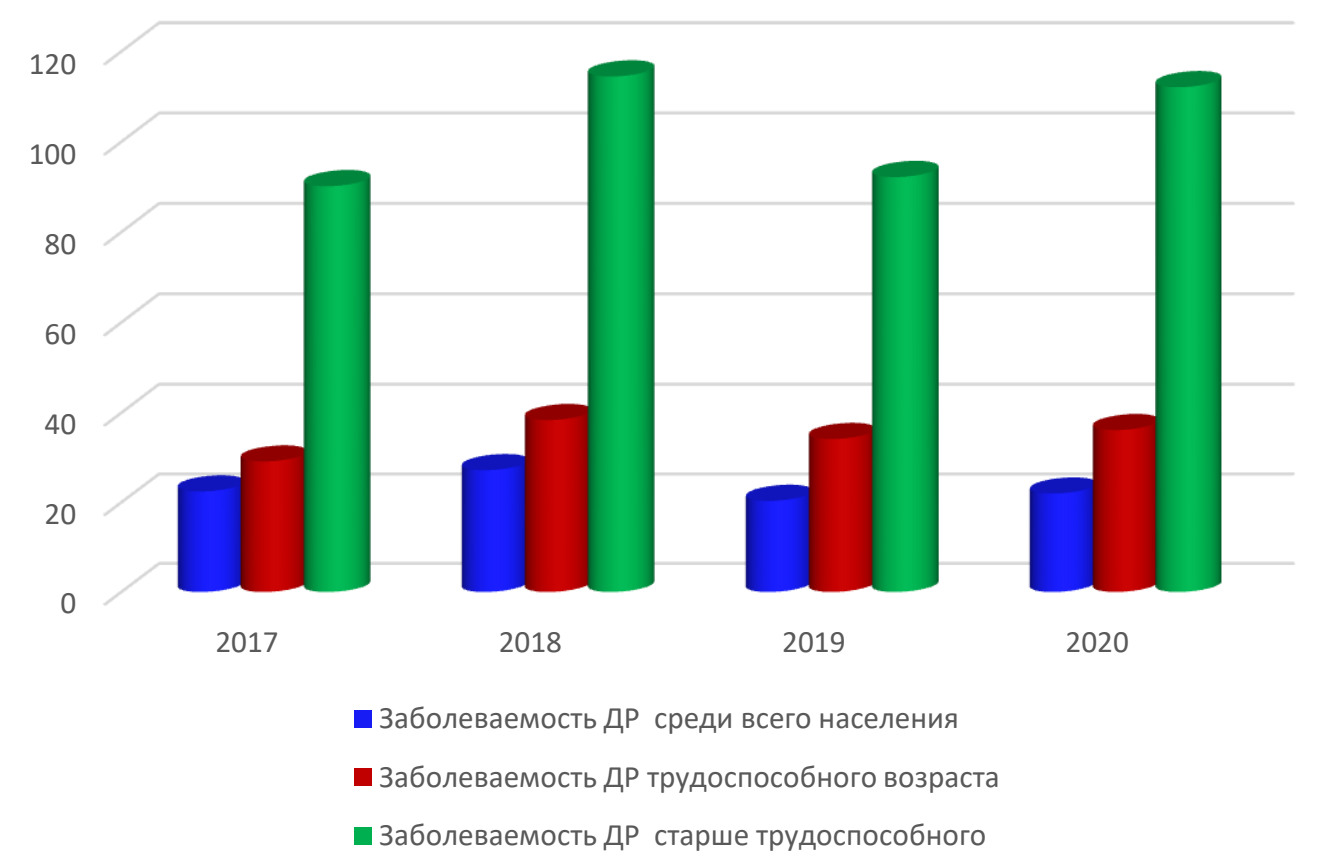

Рисунок 1. Показатели заболеваемости населения сахарным диабетом за 2017-2020 год, различных возрастных групп, в проиентах 
В Амурской области количество больных сахарным диабетом с каждым годом увеличивается от $15 \%$ до $25 \%$.

При сахарном диабете, вследствие недостаточной выработки инсулина, возникает нарушение обмена веществ, повышается уровень глюкозы в крови. Глюкоза - это источник энергии, главнейший метаболит в человеческом организме. Глюкоза поступает в наш организм с пищей.

Уровень глюкозы контролируется специальным гормоном - инсулином. Инсулин продуцируется бета-клетками эндокринного аппарата поджелудочной железы. Роль инсулина в организме исключительна. Инсулин регулирует весь энергообмен, под его воздействием глюкоза и аминокислоты проникают внутрь клеток. В жировых клетках под действием инсулина синтезируется ДНК, влияет на рост и дифференцировку других клеток, усиливает синтез белков [3, с. 18$]$.

При недостаточности инсулина возникает сахарный диабет 1-го типа, проявления которого наблюдаются при разрушении более $80 \%$ клеток Лангерганса поджелудочной железы. При нарушении чувствительности тканей к инсулину развивается сахарный диабет 2-го типа. Инсулинорезистентность проявляется даже в условиях нормального уровня инсулина. Глюкоза, не имея возможности проникнуть в клетку, циркулирует и накапливается в крови. В связи с возникшими нарушениями происходит накопление сорбитола, гликозилированного гемоглобина и гликозаминогликанов. Данные вещества поражают различные клетки организма: сорбитол вызывает катаракту, микроангиопатию и нейропатию, а поражению суставов способствуют гликозамингликаны. Сердечнососудистые нарушения, мышечная слабость развивается из-за активного распада белков. Усиление перекисного окисления липидов и последующее накопление токсических веществ приводит к повышению кетоновых тел [1, с. 97].

При сахарном диабете наиболее уязвимыми органами являются: сердце, глаза, сосуды нижних конечностей, почки.

Диабетическая ретинопатия - одно из наиболее тяжёльх осложнений сахарного диабета. Представляет собой микроангиопатию, с поражением прекапиллярных артериол, капилляров и посткапилярных венул, хотя и более крупные сосуды могут вовлекаться. Изменение сосудов характеризуются, с одной стороны, микрососудистыми окклюзиями и, с другой стороны - увеличением проницаемости сосудистой стенки и выходом жидкости в окружающие ткани. Нарушение перфузии ретинальных капилляров приводит к ишемии сетчатки и последующей атрофии. Такое осложнение сахарного диабета может вызвать снижение остроты зрения и даже полную слепоту, и как следствие привести к инвалидности. Среди пациентов, страдающих сахарным диабетом, слепота наступает гораздо чаще, чем у людей, не страдающих этим заболеванием.

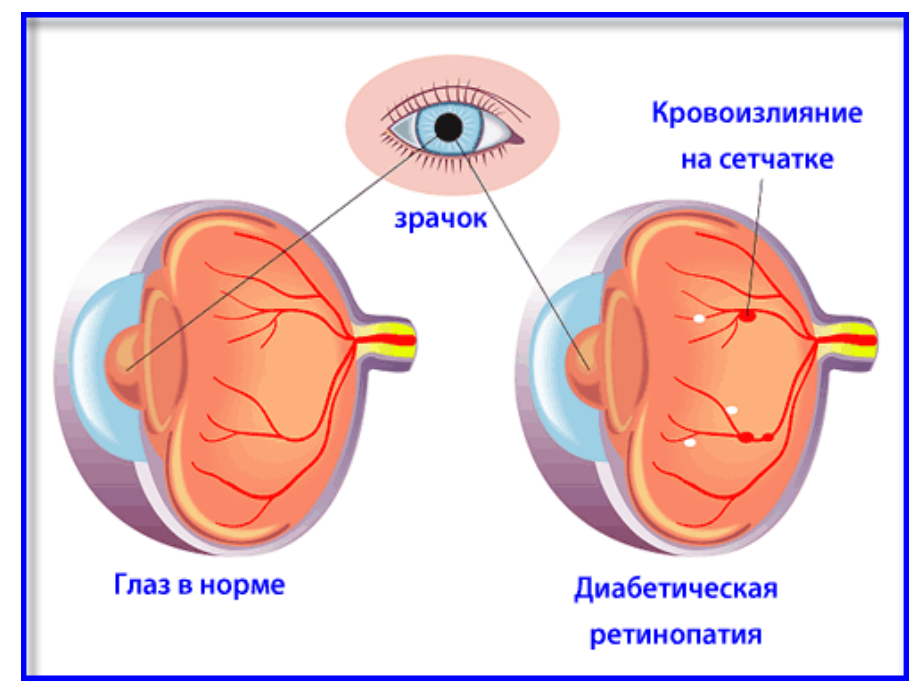

Рисунок 2. Диабетическая ретинопатия 
Ведущим фактором в профилактике, стабилизации и лечении диабетической ретинопатии является не только рациональная терапия сахарного диабета, но и организация четкой системы выявления и лечения диабетической ретинопатии, приводящая к уменьшению случаев потери зрения, повышению качества жизни.

Для устранения патологических явлений на сетчатке при диабетической ретинопатии предложено большое количество хирургических и медикаментозных методик лечения. Несмотря на большое количество исследований, проблема лекарственного лечения диабетической ретинопатии у взрослых, больных сахарным диабетом, остается одной из актуальнейших тем в офтальмологии.

Цель исследования: оценка клинической эффективности применения ретиналамина при диабетической ретинопатии.

Мною проведено офтальмологическое обследование. Под наблюдением находилось 45 пациентов (90 глаз), с разным возрастом дебюта заболевания, разной степенью метаболического контроля и продолжительностью заболевания. Из них выявлено 28 пациентов - женщины, а 17 пациентов - мужчины. Обследование включало: визометрию, биомикроскопию, прямую и обратную офтальмоскопию, ультразвуковую допплерографию глазничной артерии. Лечение ретинопатии проводилось на раннем этапе развития, с целью максимального воздействия препарата на поврежденные структуры глаза.

Используемый нами препарат относится к группе пептидных биорегуляторов ретиналамин.

Ретиналамин - комплекс пептидов, выделенных из сетчатки скота. Специфическое воздействие ретиналамин заключается в стимуляции функции клеточных элементов сетчатки, способствует улучшению функционального взаимодействия РПЭ и наружных слоев фоторецепторов, ускоряет восстановление световой чувствительности сетчатки.

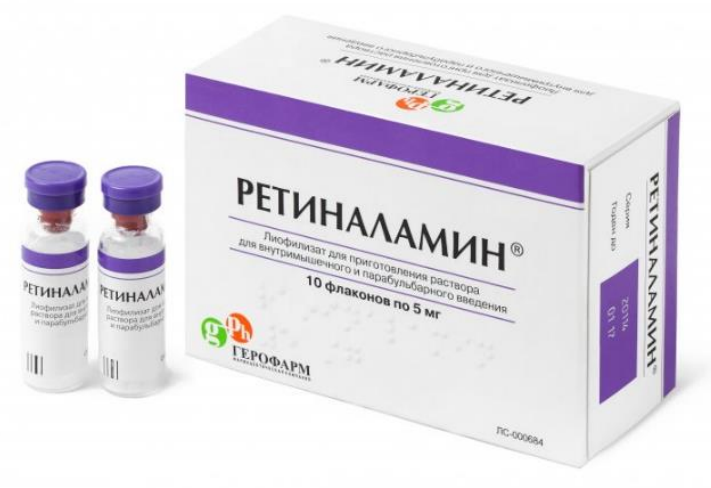

Рисунок 3. Ретиналамин

Пациенты были подразделены на следующие группы.

1-я группа - 16 пациентов (32 глаза). Средний возраст пациентов - 40 лет. На фоне основной терапии сахарного диабета (инсулин, антиоксиданты) получали ретиналамин парабульбарно 2,5 мг - ежедневно 10 дней.

2-я группа - контрольная группа, 29 пациентов (58 глаз). Средний возраст пациентов - 60 лет. Все пациенты обследовались исходно (до начала лечения), непосредственно после проведенного курса ретиналамином, через 1 месяц и далее через каждые 3 месяца. Длительность наблюдения составила 1,5 года. При контрольных визитах проводилось комплексное клиническое обследование, общим и биохимическим анализами крови, определением уровня гликемии натощак, гликированного гемоглобина, сывороточных липидов, а также индекс резистентности глазничной артерии. Кроме того, фиксировались любые побочные эффекты и изменения в сопутствующей медикаментозной терапии. 
Непосредственно после проведенного курса лечения в 1 группе произошло улучшение остроты зрения, через месяц - у 5 пациентов (10 глаз) отмечено уменьшение количества геморрагий и микроаневризм. Через 3-6 месяцев положительная динамика у 5 пациентов (10 глаз) сохранилась, отмечено улучшение еще у 2 пациентов (4 глаза). Положительная динамика по допплерографии отмечена у 5 пациентов (10 глаз) через 1 месяц, и сохранялась в течение 6 месяцев.

В контрольной группе в периоды осмотра улучшений в картине глазного дна не отмечено, через 6 месяцев у 15 пациентов количество геморрагий увеличилось. Острота зрения у остальных пациентов оставалась неизменной.

Вывод: Данные обследования показывают выраженность ретинопротекторного действия ретиналамина, его продолжительное воздействие, на фоне компенсации состояния по основному заболеванию. Отмечено улучшение картины глазного дна, сохраняющейся длительный период времени - в течение 6 месяцев. Побочных реакций организма на данный препарат у больных выявлено не было.

\title{
***
}

1. Астахов Ю.С., Лисочкина А.В., Шадричев Ф.Е. Современные направления медикаментозного лечения непролиферативной диабетической ретинопа-тии // Клиническая офтальмология. - 2003. - Т. 4. - № 3. - С. 96-101.

2. Гаврилова Н.А. Патогенетические механизмы развития диабетической ре-тинопатии, диагностика ранних стадий, прогноз и профилактика развития, дифференцированный подход к лечению: Дис. доктора мед. наук. - М., 2004.

3. Дедов И.И. Диабетическая ретинопатия: современные проблемы // Сахарный диабет. - 2008. - № 3.1. - С. 48.

\section{Плащевой В.В. \\ Изучение эффективности препарата группы натрия кромогликат при лечении аллергических конъюнктивитов}

\author{
ЛДЦ «Анкор» \\ (Россия, Благовещенск)
}

doi: 10.18411/trnio-12-2021-323

\section{Аннотация}

В статье рассмотрены вопросы тактики лечения аллергических конъюнктивитов. Проведенные исследования доказали эффективность препарата группы натрия кромогликат при лечении аллергических конъюнктивитов. Данный препарат позволяет снизить жалобы пациентов и достичь высокого терапевтического результата. Побочных реакций у пациентов не наблюдалось.

Ключевые слова: натрия кромогликат, аллергический конъюнктивит, гиперемия конъюнктивы, аллергический отёк, аллергическая реакция.

\section{Abstract}

The article discusses the issues of tactics of treatment of allergic conjunctivitis. The conducted studies have proved the effectiveness of the sodium kromoglycat group drug in the treatment of allergic conjunctivitis. This drug allows you to reduce patient complaints and achieve a high therapeutic result. No adverse reactions were observed in patients.

Keywords: sodium cromoglycate, allergic conjunctivitis, conjunctival hyperemia, allergic edema, allergic reaction.

\section{Введение}

Аллергические заболевания охватывают в среднем около 15 \% населения земного шара. В регионах с аллергической заболеваемостью повышенная чувствительность к 